\title{
Teaching Critical Reading As a Way of Teaching Critical Thinking
}

\author{
WILLIAM M. TAYLOR Oakton Community College
}

For the past sixteen years I have been teaching political science at Oakton Community College which serves the North and Northwest suburbs of Chicago. One of my primary objectives during this time has been to help my students realize that on the important questions of politics there is no one right or wrong answer; that there are many legitimate, defensible approaches to solving public policy issues; that these approaches are generally shaped by one's ideology; and that intelligent people, acting in all good faith, may never agree on what course of action to pursue. At the same time I have wanted my students to realize that this does not mean there are no answers and therefore everything is relative, but rather that even if they were never to take another course in political science they would have an obligation to develop their own political views, an obligation they don't have the right to give up by blindly accepting what they hear from politicians or political "experts", (including me). In other words, I have wanted them to develop the ability to intelligently analyze and evaluate the things they hear and read, in the process developing their own views and the ability to defend them.

Then, in $1985 \mathrm{I}$ attended a conference on critical thinking sponsored by the University of Chicago. Suddenly, I found that I had some labels I could use to describe what I had been trying to do. In addition, I came away with the realization that I needed to make some changes in the way I was teaching, changes that would help my students develop their critical thinking skills and apply them to political issues.

Among other things, I began working with Lynda Jerit, one of my colleagues from Oakton's English Department, on the development of a series of reading and writing assignments for my course in International Relations. I approached the task with a full measure of anxiety: what did I know about developing a well constructed assignment? After all, I used to simply say to my students: "Go write a research paper, and if you don't know what this is, ask your English teacher." Fortunately, my choice of Lynda as a mentor was a good one. She has studied writing at the University of lowa and has a wonderful ability to help a teacher think through exactly what s/he wishes to accomplish in a writing assignment. Through numerous drafts she kept prodding me to clarify my thinking and then put it down on paper. And she continues to help me as I engage in ongoing revision in the light of student feedback.

The result is a series of five writing assignments that focus on the critical thinking skills needed to intelligently read political articles that appear in newspapers and popular magazines, the types of writing that students will be exposed to for the rest of their lives.

What I think is most important about these five assignments is that each of them begins with a lesson that teaches the specific skill to be employed in the reading/writing assignment: first, distinguishing facts from opinion; second, determining the author's point of view and how it affects what s/he says; third, detecting fallacies; fourth, comparing and contrasting articles that take different positions on a single issue; and fifth, the skill of analyzing and evaluating a given article. In the process of teaching these skills I also introduce the students 
to the research and writing conventions of the political science discipline. Perhaps equally important is the fact that a minimum of class time is spent on teaching these skills since the assignments are all written up, bound, and sold in the bookstore as a required text.

Something else came out of the University of Chicago Conference that is important to mention since it provides something of a theoretical framework for my reading/writing assignments.

In addition to me, five other Oakton faculty attended the conference and we started meeting every Friday afternoon to educate ourselves on critical thinking. Eventually we began planning a two semester, weekly seminar for ourselves and other faculty on the whole area of critical literacy: critical thinking, critical reading, and critical writing across the curriculum. We applied for and received a FIPSE grant to support the seminar, as well as a number of other initiatives in this area. We're currently halfway through the first semester of the seminar with twenty participants, including both vo-tech and baccalaureate faculty.

One of the things we quickly came to realize is that critical thinking means different things to different people, with many of the experts seemingly convinced that their view is the only correct one. Needless to say, for us "nonexperts" this was disconcerting. Fortunately, in our seminar we have had several guest speakers who have specifically addressed this issue, namely Neil Browne and Stuart Keeley from Bowling Green and Kathryn Mohrman from Brown. In addition, I have done a great deal of reading around the topic. Without going into all of the details, let me give you my conclusions: there is no one thing that is critical thinking. Rather, there are many aspects of critical thinking such as problem solving/decision making, informal logic, disciplinary paradigms/modes of inquiry, question asking, and others. Some of these skills are required more in one discipline than another. No one person can be expected to teach all the skills of critical thinking. Instead, each of us has the responsibility to teach those skills which are most needed in our discipline. In the case of political science (as well as many other disciplines) I think those are the skills of informal logic, for these can help the student to intelligently study political issues, analyze and evaluate the competing views of how to deal with those issues, and arrive at a well thought out position which s/he is able to defend.

Let me turn now to an outline of the critical thinking skills taught in each of the lessons. In the process I will mention the disciplinary conventions that are also discussed. I will summarize the first in some detail to give you a sense of the scope of the lessons and assignments. The remaining four I will describe more briefly.

The first paper focuses on the skill of distinguishing facts from opinions. The lesson begins with a definition of fact as something that has actually happened, is true, or can be proven to the satisfaction of reasonable people. I point out that in political science, as in much of life, some facts are not easily proven, such as our conviction that democracy is the best form of government. I then distinguish opinions from facts by indicating that opinions are interpretations of facts or historical events about which there is no agreement.

There follows an explanation of the steps the reader can take to clarify the nature of the facts and opinions found in an article. With regard to facts, the students learn how to:

1. Distinguish between facts that are central to the author's argument and facts that are incidental to the argument.

2. Distinguish between facts that are common knowledge and facts that are not (and therefore need to be proven).

3. Distinguish facts from opinions that are disguised as facts.

With regard to opinions, the students 
learn how to:

1. Distinguish between opinions that are central to the author's argument and opinions that are incidental.

2. Distinguish between opinions that require justification and those that do not.

3. Distinguish between opinions the author supports with evidence and those that s/he does not support.

4. Distinguish between opinions the authors acknowledges as opinions and those s/he tries to disguise as facts.

In the course of the lesson I mention several points about the conventions of the political science discipline. I explain, for example, what standards political scientists use in deciding whether or not something should be accepted as fact. I also point out widely held "facts" (e.g. that our European allies are not carrying their share of the cost of NATO defense) are legitimately called into question and are the focus of much scholarly research. I also mention that in all disciplines intellectual honesty requires that an author clarify when he is basing his argument on a theory with which not all scholars agree.

Having completed the lesson, I then describe the assignment in detail. All of the students are to read the same article in Annual Editions: World Politics. After reading it thoroughly they are to write a brief sentence or two capsulizing the main point of the article. (At first I did not require this, but I discovered that some students had not thought to do it on their own, with the result that they were not able to do the next part of the assignment.) The students are then to quote ten facts that are key to the author's argument and five that are incidental, indicating why they think the facts are central or incidental.

Following each of the ten key facts the students are to indicate:

whether the author attempts to prove them;

- if an attempt is made, what kind of evidence is given and how persuaded the student is by the "evidence"; and, if the facts are not proven, whether they are part of the student's fund of common knowledge.

Next, the students are to quote ten opinions expressed by the author. Following each they are to indicate:

- whether it is a key or incidental opinions, and why

- whether the author acknowledges it to be an opinion or instead hides it by asserting it as a fact; and,

- whether the author supports his opinion, and if he does, indicating the type of support and whether the student finds it persuasive, and why.

The first paper, then, turns out to be a list of quotations, followed by words or phrases describing the nature of the quoted material. A typical entry may look like this:

\footnotetext{
"In his Inaugural Address, John Kennedy committed the U.S. to resist communism at all cost." This is a key opinion because. . ; it is not acknowledged but it is supported with reference to another source (book by Arthur Schlessinger Jr.); I'm not convinced because. .
}

The assignment concludes with the criteria I will use in grading their work. In this instance I indicate that this is the first in a series of papers designed to help them develop their critical thinking skills and that I do not expect them to perfect the skills in their first effort. I call their attention to the fact that it is especially difficult for neophytes to determine that something forcefully stated as a fact may in reality be an opinion and I ask them to be on the lookout for examples of this. I then indicate that their grade will reflect my overall sense of how well they do at distinguishing facts from opinions and that it will not be based on a mathematical formula related to how many "right" or "wrong" judgments they make. I don't tell them, but in fact I tend to give only A's, B's, and $C^{\prime}$ 's on the first paper, with the $C$ reserved for those who don't seem to have taken the assignment very seriously. 
The second assignment deals with the skill of determining the author's point of view, which I define as the opinion, outlook, attitude, or prejudice we have toward things we encounter in our daily lives. I indicate that one's point of view can grow out of extensive study and research, or, at the other extreme, it can result from a variety of past experiences which reside in the subconscious.

Without defining them, I call their attention to some of the more obvious points of view which could be found in any kind of writing, such as that an author can be sympathetic/unsympathetic, tolerant/intolerant, and/or cynical/trusting. I then spend several pages explaining the liberal and conservative points of view since they will regularly encounter these in political writings. The lesson ends with a discussion of the final point of view to be considered, that of the student himself. I stress the fact that if the student's point of view is similar to that of the author he may unthinkingly accept whatever is said, just as he might offhandedly reject things that reflect an opposing point of view, and that in either case the student would not be thinking for himself.

As part of my effort to orient the students to the discipline, I discuss in this lesson how different points of view can evolve into schools of thought and how the competition between these schools leads to advancements in research and knowledge.

As for the assignment, the students are required to read a given article and then:

summarize the issue or main idea the author is writing about;

- indicate the author's principle point of view or position on this issue;

- explain the reasons given by the author for why s/he holds that point of view;

- make a judgment as to whether the author is a conservative or liberal, supporting that judgment with material from the text; and finally

make a judgment about the extent to which the author's liberalism or conservatism interferes with his objectivity.
The third paper is concerned with detecting fallacies. In this instance the assignment comes first: the students are to read whatever articles in Annual Editions interest them. While doing so, they are to look for fallacies, defined as arguments that are unsound because they rely on flawed reasoning or faulty thinking. In their papers they are to quote fifteen fallacies, explaining why they consider them examples of faulty reasoning.

The rest of the lesson is an explanation of some of the more common fallacies: labeling, hasty generalization, appeal to authority, bandwagon, cardstacking, begging the question, false dilemma, false analogy, non-sequitur, unproven assumptions, special pleading, repitition, and misleading statistics. Unfortunately, each of these is all too easily illustrated in the area of political science, especially in the campaign speeches of politicians.

In the fourth assignment the students are required to select an article from $A n$ nual Editions, find another article that takes a different position on the same issue, and compare and contrast the two. Part of the lesson involves distinguishing among the different types of magazines (e.g. Reader's Digest, Time, New Republic, and Foreign Affairs), indicating which are appropriate-or inappropriate - for what uses. In the process I discuss the issue of "audience" and how it affects mode of presentation. I also give some practical advice on how they can find an article in the library that takes a different positon from the one they have chosen. I conclude the lesson with several alternative approaches the students can take to writing a comparison and contrast paper. I ask them to conclude their paper by giving a personal assessment of what they now believe about the issue based on the two articles, and why.

In the context of this lesson I try to help the students understand the difference between scholarly and popular periodicals, as well as the role of scholar- 
ly journals in the development of ideas within the discipline. I also take the opportunity to discuss William Perry's idea of "commitment within relativism," telling the students that "judgments must be made, but tentatively, and always open to revision based on the discovery of new information."

The final paper, entitled "Critical Assessment," asks the students to use all of the skills learned in the previous papers, as well as what they have learned from the course in general, to analyze and evaluate an assigned article. The lesson discusses in general how the student should proceed. I then describe the steps I went through in critically assessing an article I had assigned to them on the first day of class. At that time they were simply told to "read this article and write a two page critical assessment." Almost invariably they had gone off and done so without asking what I meant by that. I now return them to the students, along with a copy of $m y$ critical assessment of the article. This, along with the description in the lesson of how I went about it, gives the students a sense of how they should proceed. (Getting the paper back at this point also helps them get a sense of how far they have progressed since the semester began).

Having given you a sense of what the lessons and assignments are all about, let me conclude with three comments. Although the students tend to grumble about the amount of work, they freely admit how much they get out of it. I never had a student tell me that when I simply said "Go out and write a research paper." In addition, I am much more comfortable than I ever have been when grading the papers. Because I spent so much time clarifying the assignments for myself and then for the students, I feel confident that they have a clear sense of what is expected of them. But even more, I have a clear sense of what I am looking for when I grade the papers. And finally, I feel I have discovered a way to both cover the material of my course as well as teach skills that can make a difference in the lives of my students, skills which empower them to think for themselves when confronted with experts and politicians who forcefully express their views as fact.

Professor William M. Taylor, Department of Political Science, Oakton Community College, des Plaines, Illinois, 60016. 